\title{
Axiological aspect in the context of teaching philosophy
}

\author{
Marian Ambrozy - Peter Sagat
}

DOI: 10.18355/XL.2019.12.03.16

\begin{abstract}
In what way should philosophical subjects be taught from the perspective of values? In essence, there is a possibility of doing it in three distinct ways: The first one is via maintaining a certain ideological position and choosing a style of education, methods, and approaches through the prism of the subject in question. The second possibility is determined by the approach to teaching stemming from a neutral evaluative aspect, or by giving a neutrally charged portfolio. The third option is to utilize an apophatic grasp on the problem in question achieved through the negative ostracization of certain ideological positions. In this case, the differential criterion would be represented by the social consequences of historically existing models asserting concrete opinions. This paper constitutes a discussion on the process of reconciling the possibilities above.
\end{abstract}

Key words: didactics of philosophy, metaethics, training, education, dialogue

Civil and political systems have often tried, with varying degree of success, to force teachers at various levels of education to offer a curriculum tinctured philosophically, or outright ideologically. This problem is particularly noticeable from the point of view of the didactics of philosophy. It is so for several reasons. Through its methodology of science and the philosophy of science, philosophy as such shares a certain connection to sciences. After all, knowledge must resemble unity, and philosophy and science must not contradict each other. In many ways, philosophy has a close relationship with religion, as well. A certain sensibility when it comes to values may certainly be perceived in, for instance, mathematics or informatics; however, they hold a special place in philosophy, and the didactics of philosophy especially.

Values are usually tied to either metaphysics, religion, or science. "In several philosophical streams of thought of the $20^{\text {th }}$ century, an inclination to the claims that religion cannot produce justifiable cognitive claims can be found." (Karaba, 2017:192). The first and most basic question pertains to the possibility of getting to know values. Are values even knowable in their totality? This question is fundamentally linked to the certainty of scientific and religious knowledge. These topics are also interesting from the point of view of early analytic philosophy compare Floyd (Floyd, 2009).

With good reason, Kant calls for severe restrictions to be placed upon the fundamental questions of knowledge, Reason (Vernunft) leads people astray from the boundaries of such knowledge, into the territory that is impossible to get to know. This belongs to the field of Kant's metaphysics. This place is represented by three ideas - the psychological idea, the cosmological idea, and the theological idea. All three ideas are dichotomic. Free will itself is already a metaphysical postulate if ethics is at all possible. If the primary meaning of Kant's categorical imperative, given by a common sense of duty to follow our own sincere conviction, is to be replaced by the principle of not using human beings as a means for something, but a purpose, it certainly presupposes some ethical boundaries postulated by Kant himself. Kant's correction is vital to the consequences of the problem that lies at the center of this paper.

Scientific knowledge changes as time progresses. T.S. Kuhn talks about a paradigm shift. Aristotelean physics, for example, was vastly different from the 
physics of Galilei which, in turn, differs from modern-day physics with its interactions, subatomic particles, or the general theory of relativity. A paradigm shift implies the triumph of a certain scientific paradigm over the competing ones. Scientific knowledge is historically conditioned. Ladislav Kvasz reminds us of the term rupture in the history of science. This rupture entails specific breaking points that are usually juxtaposed with the developments in culture. For instance, the Pythagorean rupture was connected to evidence; the introduction of non-Euclidean geometry was conditioned by the accentuation of the role of the subject by German classical philosophy (Kvasz, 1998).

On the other hand, Kvasz also highlights the problem of inconsistency and how to reconcile it. For example, in mathematical sciences, there may come a situation where "after a shorter or longer period since revealing logical inconsistencies within a certain theory, a new logically consistent version which usually yields similar conclusions than its inconsistent counterpart, may be created" (Kvasz, 2012a:95). Ruptures in mathematical sciences are, however, breaking points. A contemporary historian or a philosopher of science cannot, under any circumstances, cling to the cumulativistic vision. The naïve post-Enlightenment notion of building up a positivistic vision of science according to Comte, a science that rests on the shoulders of physics along with the employment of mathematical methods, was later amended by Poincaré's condition that continually improves and softens the known invariants. Such idealized fantasies do not correlate to the history of science. "The accuracy of the argumentation employed by Kuhn was sufficient enough for him to point out the inadequacy of the cumulativistic image of science" (Kvasz, 2012b:168). Even anticumulativism is called into question, e.g., in the work of Larry Laudan. "Against relativist arguments, Laudan maintains that the hierarchical model works well enough for certain cases of rational consensus in science. However, it does not work in general for two important reasons" (Doppelt, 1986:225).

Many contemporary scientific theories (in physics, for example) are outside of the sufficient empirical framework that would support them by subjecting them to scientific validation in the form of experiments and measurements. Moreover, so, they remain on the level of their theoretical postulations without the slightest empirical correlation. Their valuation on the praxiological level thus becomes problematic. For instance, string theory has gained only a single relevant theoretical result: it has managed to explain the construction of black holes by P-branes. Safe for that, string theory has also predicted new, hypothetical particles as well as new types of symmetries; nevertheless, neither the particles nor the symmetries have been empirically tested. String theory is beyond the scope of the empirical capabilities of modern physics because "its main detraction is its non-verifiability" (Dubnicka, 2008:700). Despite its shortcomings, string theory enjoys the interest of many theoretical physicists - from the point of view of the sociology of science; it could be said that it is a theory that constitutes the center of interest for many scientists, institutions, and considerable resources and energy are being devoted to it.

On the other hand, the disputes concerning the explanation of quantum mechanics are beginning to mount up. It is not the concern of exotic interpretation like the one of $\mathrm{H}$. Everett whose wasting of actual worlds constitutes a gross negation of Occam's razor, but rather the concern of long-term disputes between the classical interpretations that adhere to Einstein, and the Copenhagen interpretation that follows the ideas of N. Bohr. The latest results of notable physicists seem to lean in the direction of Einstein by pointing out the mistakes made by Bohr (Procházka, Lokajíček, and Kundrát, 2016). The existence of the interpretation of quantum mechanics is at stake because if classical interpretations based on Einstein's rejection of Bohr's conclusions are right, then physics has to adhere to the causal-ontological approach. Scientific truth as a value, as it can be seen from the given an example, is

XLinguae, Volume 11, Issue 3, June 2018, ISSN 1337-8384, eISSN 2453-711X 
not always unambiguous when it comes to the history of science or even from the point of view of present-day science.

Sometimes, it may become problematic to define the term rationality along with all of the different contexts that accompany it. Nosek (Nosek, 2007) distinguishes two basic types of rationality: 1 . the functional type of rationality, and 2 . the analytical-constructive type of rationality. Nosek understands the core of the logical type of rationality to be "the logical" (das Logische) expressed by G. Frege. The analytical-constructive type of rationality dwells in the separation of a whole into its subsequent parts which are then reconstructed into a different whole. It can be found in the system of spelling letters, partly in the metaphysical notions of Empedocles and Anaxagoras, in Democritus, in Plato's Timaeus, etc. As Nosek notes, in science, rationality is viewed by some philosophers as a matter of scientific convention, that which scientists consider to be scientific rationality (Fajkus, 2005), or a higher-level intellectual activity with its applications (Tondl, 1998). From a historical perspective, such examples would be embodied in the ties of antique rationality to finitism (it resonates, for example, in Wittgenstein's philosophy of mathematics), the fear of current infinity, and its preference in the historical Chinese thought. Just to illustrate the complexity of the situation, from a phenomenological viewpoint, there exist two different worlds: the world of scientific rationality, and the world of common, everyday rationality (Zouhar, 2016:15). As stated by Jankel, Mišúnová Hudáková and Mišún, "on the assumption of rationality are based normative theories" (Jankelova, Misunova Hudakova, and Misun 2013: 740).

Religion comes in a relationship with many disciplines, even with tourism compare (Hvizdova, 2018). The relationship between science and religion is found in a strange and uncertain position, mainly when the focus is put on physics. Physics is incapable of providing religion, mainly theologia naturalis, with any convincing evidence as to the existence or inexistence of God. The opposite approach to the founding of religion is by S. A. Kierkegaard. In the area of reading, Valls Boix (Valls Boix, 2018) deals with this topic. However, it can provide certain clues that are potentially interesting for the ideological position of religion. (Mahrik, Kralik, Tavilla, 2018; Mahrik, Pavlikova, Root, 2018) Let us look closer at some consequential facts concerning the relationship between religion and science, most of all, physics.

The science of physics offers some clues that are interesting from the point of view of religion. J. Krempaský focuses on the well-known question of the physicist Weinberg - how is it possible that at the very beginning of the universe, a required amount of matter appeared (Weinberg, 1983)? Fluctuation could have generated a random amount of matter. However, in order for life to flourish, the amount of matter in existence had to be precisely $10^{53} \mathrm{~kg}$. For that, there is no definitive answer in physics (Krempaský 2016:13). In this context, Slovak physicist Krempaský also highlights another important question - how is the existence of particle matter instead of only radiation possible? Physics tells us that the physical vacuum generates particles and anti-particles in the same amounts that subsequently annihilate each other. Thus electromagnetic radiation is born. Krempaský points out a postulate that may be able to explain the emergence of particles. This postulate constitutes a certain minimal asymmetry. However, this asymmetry has to be incredibly small - one particle to a million annihilations. It is due to this principle that matter in the form of particles exists.

Physics can attempt to answer the ages-old question also formulated by Leibniz - why is there something instead of nothing. This question was revived in the $20^{\text {th }}$ century by Heidegger, mainly through the famous formulation of the most fundamental of metaphysical questions - what is the purpose of being (Heidegger, 2001). Krempaský also reflects on this question when he points to Krauss's proclamation that nothing is more unstable than something (Krauss, 2012). It means a 
physical vacuum that does not contain any form of materia, merely energy. In this case, it is about the instability of the vacuum coupled with generating an equal amount of positive and negative energy, and this process had to end soon enough for the proper amount of matter to form in order for life to emerge. When it comes to the question of the creation of the universe, there are no answers in the sense of quantifiable data yet. Krempaský notes that even though there exists an equal amount of positive and negative charge, the configuration of energy, however, is not yet known. Generating matter out of vacuum could be anticipated by Hawking with his theory on the evaporation of black holes, which was not yet empirically confirmed. Nevertheless, the Russian physicist Pomeranchuk has predicted that the physics of the future will be the physics of the vacuum.

The birth of the universe in time is documented by three clear pieces of evidence. The first two pieces of evidence are the redshift, explained based on the Doppler effect, and the Cosmic Microwave Background radiation. The third and final piece of evidence is the presence of helium in the universe, the shear amount of which could not have possibly been created by the stellar synthesis of the elements. Each of the three mentioned physical theories is empirically verified and well-established. The beginning of the universe is also interpreted in accordance with the biblical view of the creation of the universe. Modern-day physics and Christian, Judaist, and Islamic theologies talk about the birth of the universe in time, which is not in contradiction to contemporary cosmology.

From the point of view of the relationship between physics and religion, the anthropic principle is also notable. The basic question concerning the anthropic principle is whether we are to take it seriously, or just as a way out of the conundrum out of necessity (Krempasky, 2016:92). Some physicists recommend waiting for the formulation of the theory of everything, other physicists like A. Linde, W. Dyson, H. Ross, or D. Page, etc. recognize the anthropic principle as a valid theory. The anthropic principle can be divided into its strong, weak, and final forms. The theory opposing the anthropic principle is the multiverse theory, according to which there is a large number of universes in some of which human beings have emerged, in others they have not. The existence of parallel universes in the sense of possibilism is a case of wasting ontological entities. The number of parallel universes would thus have to be incredibly large. From a metaphysical standpoint, it would constitute an immensely complicated project, akin to that of Hugh Everett. Stephen Weinberg had remarked to this theory that it is sheer non-sense because, in order for a system of empirically possible worlds to function in such an argumentation, there would have to be an infinite number of universes.

From an ontological perspective, a principle of tenacity, rather than wasting various parallel universes, is more likely to be accepted. That is why the anthropic principle in physics is more likely than a large number of different universes. The anthropic principle also involves other serious physical matters. A barely perceivable change in the fundamental physical constants would precipitate such large changes that the existence of life in the universe would be impossible. These constants are the gravitational constant, the speed of light c, the Planck constant, the Hubble constant, the mass of known atomic particles. If, for instance, the electromagnetic interaction was stronger, the luminous intensity of the stars would not be as intense. In the case of weaker electromagnetic interaction, the luminous intensity of the stars would be more intense but much shorter (Krumpolc, 2013). The universe is expanding into a physical vacuum. An important thing is also the ratio between the expansion of the universe and gravitational interaction. A change in this ratio would either cause the universe to collapse in on itself, or the expansion of the universe would have been so fast that it would preclude the emergence of celestial bodies. The fact that the universe is expanding and that this expansion is gradually accelerating is also of consequence.

XLinguae, Volume 11, Issue 3, June 2018, ISSN 1337-8384, eISSN 2453-711X 
The asymmetry present at the beginning of the universe is ascribed to a hypothetical particle $\mathrm{x}$. Its detection is conditioned by a particle accelerator more powerful than the one at CERN.

The clues about the common ground when it comes to the explanation of the relationship between religion and physics are many. Despite that, neither physics, nor any other science for that matter, is capable of proving the existence of any spiritual being which is why it cannot prefer any kind of religion when it comes to the question of values, whether from the perspective of knowledge or the perspective of axiology. There is no certainty concerning the world-view, and that is why the floor is open for faith. It is also the reason for the existence of so many different religions. So far, this article has shown that problems persist even in the interpretation of some scientific theories like quantum mechanics, for example. Diverse epochs of scientific development tend to view the same phenomena differently, whether it involves Kvasz's ruptures that he mainly places into the history of mathematics, or it concerns a variety of paradigms present in the history of chemistry (for instance, the difference among alchemy, iatrochemistry, and phlogiston theory) (Smik, 1988).

This situation might get more complicated when social philosophy is introduced into the mix. The deprivation of a neutral viewpoint from the perspective of social philosophy may effectively cause notable deformations in the field of historical interpretation. The field of history of philosophy may also be affected. Any kind of a philosophy of the history of philosophy might nolens volens alter the original concepts of the individual philosophers so that they would fit into a given scheme, much like the notorious Hegel's History of Philosophy. A somewhat different kind of situation is present in the area of evaluating social philosophy from the point of view of its individual ideological positions. If this evaluation comes from the perspective of a specific ideological position, the antipode streams are often very negatively evaluated when putting in mutual confrontation. Sometimes, it does not even have to involve antipodes from social philosophy, mainly when it comes to the political connotations of a specific problem. From a political experience, it is wellknown that it is the animosity among the coalition partners that is the most prominent. Negative relationships often dominate the connections among neighboring sociophilosophical positions - anarchists and Marxists, Marxists-Leninists and nonLeninists, etc. This is the reason for the emergence of a serious issue: is it even possible to connect pedagogy - didactic approaches - to ideologically tinctured views on science, philosophy, or history? Moreover, if so, to what extent can this perspective be employed?

"According to Kant, human being is, from the perspective of their empirical nature, more evil than good because their animal egotism often forces them to be mischievous, malicious, power-hungry, acquisitive, with no regard to the presence of their tendency towards sociability and the gift for moving towards humanism and personal dignity" (Belas, 2005:257). In connection to this, it would be appropriate to revisit Kant's amendment of the original version of his categorical imperative. The first version of his categorical imperative is quite clear. However, human conscience allows for a variety of possibilities concerning the enactment of those rules. The second version offers certain boundaries - a human being must never become used as a means to an end but should become that very end instead. In this sense, it is appropriate, however carefully, to differentiate socio-philosophical teachings. However, where does one draw the line, especially when nearly every sociophilosophical doctrine is exploitable? One must distance himself from the ethics of social implications, according to which the important thing is the result and success, instead of its implications.

On the contrary, we agree with Abelard, who believes that it is the intention and not implication, which is important. From the perspective of intention, such social doctrines as the ones that encompass an implicitly present repressive element within 
them in the form of a collective enemy which needs to be eliminated could be considered contradictory to the second version of Kant's imperative. This collective enemy can be represented by an enemy class (businessmen), ethnic group (the Jews), or any group that can be labeled a group with collective guilt. Hostility towards such group must stem directly from the essence of the socio-philosophical teaching, and it must be implicitly present in it. In such case, one can claim that it contradicts the second version of Kant's categorical imperative. Contradicting the first version of the imperative would imply an intrinsic inconsistency of a philosophical position. The teaching which put in the forefront the image of a human being that cannot be thought of the end product but his place is elsewhere than in the superlative notions about the way he is treated, carry within themselves a hostile stance towards a group of people. They may be considered dangerous from the point of view of their content, not their exploitability. Even an originally pacifistic idea may be exploited, for example, the notion of the people governing themselves. Was it not the exploitation of such a notion that was responsible for attacks on sovereign nations (Iraq, Yugoslavia, and Libya)? The harmfulness of the aforementioned ideological positions can be perceived implicitly, based on the repressive element that is consistently present in the social doctrine.

Based on the contradictory second form of Kant's categorical imperative, several important issues rise up. It is difficult to a priori agree with the teachings that contradict it in the sense of the implementation of the repressive part of his theory. It can be said that concerning the uncertainty of any metaphysical stance as well as restricted reliability of scientific results from the point of view of paradigms, ruptures, etc., it is difficult to accept a model in which a certain group of people is being repressed based on metaphysical or scientific propositions. Similar contingencies are difficult, or outright impossible to be proven true. For the given reasons, from this article's perspective, it is possible to discount similar ideological positions as those from the perspective of which it is possible to propose some interpretation based on the pedagogical-didactic process. That is not all, however. It is also possible to maintain an ideological position that points out the repressive sides of the mentioned teaching; therefore, to apophatically describe the part of the socio-philosophical doctrine as being contradictory to Kant's second formulation of his categorical imperative. A cataphatic approach - from the point of view of skeptical arguments that were mentioned above - is certainly not possible.

From the presented propositions, new questions and problems arise. Is it possible to punish the maintaining of ideological positions that are in opposition to Kant's second formulation of his categorical imperative by law? In some legal systems it is possible, but only selectively. It is not the right thing to do, however. Firstly, no one should be discriminated or outright prosecuted solely based on their opinions. The second element here is the selective prosecution of the expression of some chosen socio-philosophical positions concerning the wide portfolio of doctrines that are in opposition to the aforementioned second version of Kant's categorical imperative. As long as the bearers of such opinions are to be prosecuted for their ideological expression (something that I strictly oppose), the deviousness of such an approach will grow exponentially when it comes to the selective ideological positions among those that are carriers of the repressive element of the doctrine and the principle of a collective enemy. What is especially worthy of condemnation is when in the course of legal or moral prosecution of an individual, the terminology of one of the doctrines that encompass a repressive element or the principle of collective guilt is applied. (Kralik, Lenovsky, Pavlikova, 2018). This principle can also be used to solve problems of cultural dialogue (Dupkala, Ayan, 2017). This issue is current, especially in connection with the various dangers associated with migrants from Islamic states (Khaled, Cauda, Benca, et al., 2016). On this question, we agree with the author

XLinguae, Volume 11, Issue 3, June 2018, ISSN 1337-8384, eISSN 2453-711X 
Storoška: "Biblical basis is constitutive to our understanding of the nature of human dignity, the definition of which cannot be (in the European context) separated from the anthropological understanding that is derived from the image of human being as found in the book of Genesis" (Storoska, 2018:61). Greco offers similar religious argumentation: „Because the spirit, pneuma, is the fundament of the personal identification and self-identification" (Greco, 2017:83).

For pedagogy and didactics, and for the didactics of philosophy, especially, important consequences emerge from what has been stated in the course of this article. Is the explanation (of the history of philosophy, a system of philosophy, problems of philosophy) from a neutral standpoint possible? First of all, it is imperative to realize the danger of a didactic approach that discusses a philosophical interpretation from just one philosophical position. From the point of view of the didactics of philosophy, such an approach is completely inappropriate. For example, the Hegelian interpretation of pre-Socratics when it comes to teaching philosophy at grammar school is inappropriate, similarly to the presentation of pre-Socratics as a fight between philosophers who have maintained the position of either materialism or idealism. The need for a neutral perspective presupposes a high level of erudition and certain pedagogical experience on the part of the teacher.

In opposition to the given didactic approach stands a neutral one that does not attempt to evaluate or for that matter offer a perspective on philosophers, branches of philosophy, or philosophical issues. From the point of view of the didactics of philosophy, this position seems to be very fruitful. However, apophatically, the interpretation and the teacher doing the interpreting should, from a neutral standpoint, highlight certain parts of the doctrines that perceive a human being only as a means to an end for a different group of people (the proletariat, the Aryan race, etc.), and call to attention their repressive elements. Likewise, the teacher can outline the problem of the gender pay gap (Balcar, Filipova, Machova, 2012). By utilizing such an approach in connection with the effort to install critical thinking and correctness from the point of view of the philosophical-methodological skepticism, it becomes possible to adequately work within the scope of partial tasks that the didactics of philosophy entails (interpretation, evaluation, solidifying that which has been taught, etc.).

Nevertheless, even when it comes to solidifying what has been taught, a philosopher should pick out those parts of the given socio-philosophical system which carry the repressive element, and views a certain part of the population as a means to an end, instead of the end itself. "If we are to face the real threat of nihilism and axiological relativism that crush the soul of today's man and for the benefit of which many solid arguments exist, the only thing that remains is for us to rethink once again the most fundamental of human experience that is, in relation to its common cultural facilitation, made taboo or outright ignored, and point out its positive side" (Sucharek, 2017:427). The role of a teacher of philosophy is certainly not to prioritize a certain philosophical, ideological position and prompt towards the ostracization or criminalization of the followers of certain philosophical notions or social doctrines.

There is also a pragmatic concept of teaching and learning. "Between the transcendental and the empirical, the philosophical pragmatics gives us instruments to see the teaching action as the representation of a certain worldview, grounded on rules of a conventional nature which, therefore, cannot be uncovered by the pupil, but, at the same time, constitute the conditions for the meaning so that the pupil, once persuaded by the teacher, can organize his/her experience in a different way, oriented by these rules" (Gottschalk, 2017:459).

\section{Conclusion}

The plurality of values, attitudes, and convictions must be sovereignly respected. A teaching philosophy is no exception. The most recommended is the 
positivistic approach to interpretation, evaluation, and solidifying that which has been taught, which offers a wide portfolio of interpretations and evaluations of the various branches of philosophy and their issues from the perspective of the plurality of thought. However, in connection with the complete openness of the axiological system, a teacher of philosophy should also consider the connection with various interpretations and philosophical positions that contain elements of degrading a human being to a mere means to an end, or even maintain a stance against certain groups of people in a negative way. In accord with Kant's corrections to the original version of his imperative, the apophatic delimitations of particular negative aspect in connection with some philosophical issues are advised. Excessive zeal and the transposition from the apophatic to the cataphatic evaluation would result in the abandonment of the philosophical-methodological skepticism as one of the fundamental principles of philosophical examination. The interpretation of the history of philosophy or systematic philosophy must not be one-sided. Carefully, in close accordance with the principle of philosophical-methodological skepticism, a teacher of philosophy may assume a critical stance towards those philosophical positions which are a priori aimed at certain groups of people, and degrade them to a means to an end. In this sense, a vision of a narrow path that a teacher of philosophy should take unfolds. It is a teacher who, on the one hand, ideally does not favor any philosophical approaches or positions, and on the other hand, calls to attention the danger embedded in the content of those philosophical positions that are a priori aimed against human beings.

The paper was written as part of the tasks of the „Philosophy - the dominant part of civic education at the high school in the Slovak Republic through the prism of didactics in the ethical context, “ supported by institutional grants IG-KSV-ET03/2016/2.1.5.

\section{Bibliographic references}

BALCAR, J. - FILIPOVA, L. - MACHOVA, Z. 2012. Gender Wage Gap in the Czech Republic: First Descriptive Analysis Based on Survey 2011. In: Review of Economic Perspectives, Vol. 12, n. 3, pp. 151 - 167. ISSN 1804-1663.

BELAS, L. 2005. Social consequences of Kant's ethic, In: Filozofia Vol. 60 n. 4, pp. 254 - 268. ISSN 0046-385X.

DOPPELT, G. 1986. Relativism and the Reticulational Model of Scientific Rationality. In: Synthese, Vol. 69 No. 2, pp. 225 - 252. ISSN 0039-7857.

DUBNICKA, J. 2008. The theory of strings and the physical picture of the world. In: Filozofia, Vol. 63, n. 8, pp. 695 - 703. ISSN 0046-385X.

DUPKALA, R. - AYAN, A. 2017. On some problems of the dialogue of cultures: an attempt to christian's and muslim's complementarity, In: International Scientific Conference on Migration: Religions without Borders - European and American Perspectives, Trnava: Trnava Univ., pp. $130-141$.

FAJKUS, B. 2005. Filosofie a metodologie vedy, vyvoj, soucasnost a perspektivy. Praha: Academia, $340 \mathrm{p}$.

FLOYD, J. 2009. Recent themes in the history of early analytic philosophy, In: Journal of the History of Philosophy, Vol. 47, n. 2, pp. 157 - 200. ISSN 0022-5053.

GRECO, P. 2017. The principles of the existential personalism in the context of the Byzantine anthtopology, In: Konstantinove Listy, Vol. 10, n. 1, pp. 83 - 97. ISSN 1337-8740.

GOTTSCHALK, C. M. C. 2007. A pragmatic conception of teaching and learning, In: Educacao e Pesquisa, Vol. 33, n. 3, pp. 459 - 470. ISSN 1517-9702.

HEIDEGGER, M. 2001. Sein und Zeit. Tubingen: May Niemeyer Verlag, p. 458.

XLinguae, Volume 11, Issue 3, June 2018, ISSN 1337-8384, eISSN 2453-711X 
HVIZDOVA, E. 2018. Religious tourism and its socio-economics dimensions, In: European Journal of Science and Theology, Vol. 14, n. 2, pp. 89 - 98. ISSN 18410464 .

JANKELOVA, N. - HUDAKOVA MISUNOVA I. - MISUN, J. 2013. Vyznam strategickeho rozhodovania $\mathrm{v}$ mikropodnikoch a velmi malych podnikoch na priklade Slovenskej republiky, In: Ekonomicky casopis, Vol. 61, n. 7, pp. 737 - 756. ISSN 0013-3035.

KARABA. M. 2017. Aplikacia vybranych vedeckych metodologii na otazky nabozenskeho poznania. In: Filozofia, Vol. 72, n. 3, pp. 192 - 203. ISSN 0046-385X.

KHALED, I. - CAUDA, R., - BENCA, J. et al. 2016. Screen or not to screen? 7 questions in prevention of infection from refugees and migrants, In: Clinical Social Work and Health Intervention, Vol. 7, n. 3, pp. 16 - 18. ISSN 2222-386X.

KRALIK, R. - LENOVSKY, L. - PAVLIKOVA, M. 2018. A few comments on identity and culture of one ethnic minority in central Europe. In: European Journal of Science and Theology, vol. 14, no. 6, pp. 63 - 76, ISSN 2393-4727.

KRAUSS, L. M. 2012. A Universe from Nothing. New York - London - Toronto Sydney - New Delhi: Free Press, p. 240.

KREMPASKY, J. 2016. Krestan v tretom tisicroci. Bratislava: Luc, p. 248.

KRUMPOLC, E. 2013. A dialogue between theology and other sciences: its significance and implementation at sts Cyril and Methodius Faculty of theology Palacky University. In: Studia Theologica, Vol. 15, n. 4, pp. 125 - 133. ISSN 12128570.

KVASZ, L. 1998. History of geometry and the development of the form of its language. In: Synthese, Vol. 116, n. 2, pp. 141 - 186. ISSN 0039-7857.

KVASZ, L. 2012a. Degrees of inconstistency. In: Organon F, Vol. 19, Suppl. 1, pp. 95 - 115. ISSN 1335-0668.

KVASZ, L. 2012b. Kuhn's structure of scientific revolutions between sociology and epistemology. In: Teorie Vedy / Theory of Science, Vol. 34, n. 2, pp. 167 - 187. ISSN 1210-0250.

MAHRIK, T. - KRALIK, R. - TAVILLA, I. 2018. Ethics in the light of subjectivity Kierkegaard and Levinas, In: Astra Salvensis, vol. 6, pp. 488-500. ISSN 2393-4727.

MAHRIK, T. - PAVLIKOVA, M. - ROOT, J. 2018. Importance of the incarnation in the works of C.S. Lewis and S. Kierkegaard. In: European Journal of Science and Theology, vol. 14, no. 2, pp. 43 - 53, ISSN 2393-4727.

NOSEK, J. 2007. Veda a zdravy rozum: Komparativni studie dvou kompetenci racionality. Plzen: Vydavatelstvi Zapadoceske univerzity, $190 \mathrm{p}$.

PROCHAZKA, J. - LOKAJICEK, M. V. - KUNDRAT, V. 2016. Dependence of elastic hadron collisions on impact parameter, In: European Physical Journal Plus, Vol. 131, n. 5, 147, pp. 1 - 19. ISSN 2190-5444.

SMIK, L. 1988. Dejiny prirodnych vied so zameranim na chemiu, Kosice: Rektorat UPJS, p. 151.

STOROSKA, M. 2018. The book of Genezis as foundation for the european's civilisation's concept of social help, In: European Journal of Science and Theology, Vol. 14, n. 1, pp. 61 - 74. ISSN 2393-4727.

SUCHAREK, P. 2017. Reconciliation is not Forgiveness. Praise of Forgiveness. In: Filozofia, Vol. 72, n. 6, pp. 417 - 428. ISSN 0046-385X.

TONDL. L. 1998. What is the thematic structure of science?. In: Journal of General Philosophy of Science, Vol. 29, n. 2, pp. 245 - 264. ISSN 0925-4560.

VALLS BOIX, J. E. 2018. Kierkegaard, the author without an audience. To Tidsaldre and some notes on reading, In: Contrastes, Vol. 23, n. 1, pp. 21 - 41. ISSN 11364076.

WEINBERG, S. 1983. The first minutes. A Modern View of the Origin of the Universe: London: Fontana, p. 224. 
ZOUHAR, J. 2016. Racionalita a kazdodennost. In: Studia Philosophica, Vol. 63, n. 2, pp. 7 - 16. ISSN 1803-7445.

Words: 5674

Characters: $36799(20,44$ standard pages $)$

PhDr. Marián Ambrozy, PhD., MBA

College of International Business ISM Slovakia in Prešov

Prešov,

Slovakia

ambrozy@ismpo.sk

Mgr. et Mgr. Peter Šagát, PhD

Assistant profesor

Prince Sultan University

Riyadh,

Saudi Arabia

sagat@ seznam.cz 